\title{
Kontrollü Doğrusal Katılaştırılan Al-Cu Alaşımının Mikroyapısı, Mekanik ve Elektriksel Özelliklerinin Katılaştırma Hızına Bağlı Değişimi
}

\author{
Variations with Growth Rate of the Microstructural, Mechanical and Electrical Properties \\ of Directionally Solidified the Al-Cu Alloy
}

\author{
Sevda ENGİN*1,a, Uğur BÜYÜ̈K ${ }^{2, b}$ \\ ${ }^{l}$ Dumlupinar Üniversitesi, Simav Teknoloji Fakültesi, Enerji Sistemleri Mühendisliğ̈i, 43500, Simav, Kütahya \\ ${ }^{2}$ Erciyes Üniversitesi, Eğitim Fakültesi, Matematik ve Fen Bilimleri Eğitimi Bölümü, 38039, Kayseri
}

\author{
• Geliş tarihi / Received: 08.11.2017 • Düzeltilerek geliş tarihi / Received in revised form: 18.01.2018 • Kabul tarihi / Accepted: 25.01.2018
}

\begin{abstract}
$\ddot{O} z$
$\mathrm{Al}-\mathrm{Cu}$ alaşımı temel alaşımlar içinde tanımlanması nedeniyle endüstride oldukça fazla kullanım alanı bulmasına rağmen elde edilen alaşımın kontrolsüz döküm hali her zaman istenilen özellik ve performansa sahip değildir. İstenilen özellik ve performansta üretim için katılaştırma koşulları değiştirilir ve bu değişime bağlı olarak elde edilen sonuçların değerlendirilmesi yapılır. Katılaştırma koşullarından katılaştırma hızının etkisi ile mikroyapı özelliklerinin değişimi; malzemelerin mekanik, elektriksel ve 1sısal özelliklerini de etkilediği bilinmektedir. Bu nedenle mikroyapı değerlendirmesinin en doğru șekilde yapılabileceği ötektik Al-\%33ağ. Cu bileșeninin faz diyagramı yardımıyla belirlenmesinden sonra Bridgman tipi firın vasitasıyla sabit sıcaklık gradyenti $(\mathrm{G}=8.50 \mathrm{~K} / \mathrm{mm})$ ve beş farklı katılaştırma hızında $(\mathrm{V}=8.25-164.80 \mu \mathrm{m} / \mathrm{s})$ kontrollü doğrusal katılaştırma deneyleri yapılmıştır. Böylece katılaştırma hızının mikroyapı üzerine etkisi ve mikroyapıdaki değişimin etkisiyle mekanik özelliklerden mikrosertlik, çekmedayanım ve elektriksel özdirenç değerlerinin değişimi araştırılmıștır. Mikroyapı, katılaştırma hızı, mikrosertlik, çekmedayanım ve elektriksel özdirenç değerleri arasındaki ilişkileri ortaya koyabilmek için lineer regrasyon analizi ve HallPetch tipi bağıntılar kullanılmıştır. Ayrıca elde edilen sonuçlar benzer deneysel sonuçlarla kıyaslanmıştır.
\end{abstract}

Anahtar kelimeler: Alüminyum alaşımları, Çekme-dayanım, Elektriksel özdirenç, Kontrollü doğrusal katılaştırma, Mikrosertlik, Mikroyapı

\begin{abstract}
Although it has a lot of usage area in the industry because the Al-Cu alloy is defined among the base alloys, the uncontrolled solidified casting of this alloy does not always have the desired properties and performance. For the production of $\mathrm{Al}-\mathrm{Cu}$ alloys with superior properties, the solidification parameters known as the solidification rate, temperature gradient and composition ratio are changed and the results of this change are evaluated. It is known that changing the properties of the microstructure by growth rate affects the mechanical, electrical and thermal properties of the materials. For this reason, Al-\%33 wt. Cu eutectic composition to carrying out correctly microstructure evaluation was prepared, then controlled solidification experiments were carried out by a Bridgman type furnace at a constant temperature gradient $(G=8.50 \mathrm{~K} / \mathrm{mm})$ and at five different growth ratios $(V=8.25-164.80 \mu \mathrm{m} / \mathrm{s})$. Thus, the effect of the growth rate on the microstructure was investigated and values of microhardness, tensile strength and electrical resistivity were investigated with the effect of change in the microstructure. Both linear regression analysis and Hall-Petch type correlations were used to determine the relationship between microstructure, microhardness, tensile strength and electrical resistivity values. The results obtained in this work were compared with the previous similar experimental results.
\end{abstract}

Keywords: Aluminum alloys, Tensile-strength, Electrical resistivity, Controlled directionally solidification, Microhardness, Microstructure

*a Sevda ENGIN; sevda.engin@dpu.edu.tr; Tel: (0274) 513 79 17/1058; orcid.org/0000-0001-8746-8770

${ }^{\mathrm{b}}$ orcid.org/0000-0002-6830-8349 


\section{Giriş}

Malzemeyi oluşturan alaşım elementleri ve buna bağlı olarak elde edilen mikroyapı, malzeme bilimi ve mühendisliğinin merkezinde yer alıp malzeme işleme ve performansı arasındaki stratejik bağ $\breve{1}_{1}$ oluşturmaktadır (Boettinger vd., 2000; Jones, 2005). Bu nedenle malzemelerin işlenmesi sürecinde meydana gelebilecek mikroyapısal hataları en alt seviyelere indirmek ve yüksek performansa sahip malzeme üretimini gerçekleştirebilmek için malzemelerin mikroyapısını kontrol etmek her geçen gün daha da önemli hale gelmektedir. Mikroyap1 konusunda elde edilen bilimsel veriler yardımıyla malzemelerin özelliklerini ve performansını tahmin edebileceğimiz, simülasyonlar ve teorik modeller geliştirilmektedir. Ayrıca uygun veri tabanları sayesinde özel uygulamalar için mikroyapı şartlarının ve buna bağlı olarak performansin önceden belirlenmesiyle de endüstride zaman ve maaliyet kazanımı sağlanmaktadır. (Hecht vd., 2004).

Malzemelerin mikroyapısını en çok etkileyen hususlar ise malzemelerin üretildiği bileşim $\left(C_{o}\right)$ ve katılaştırma sürecidir (Hecht vd., 2004). Katılaştırma, malzemenin bileşiminin $\left(C_{o}\right)$, sıcaklık gradyentinin $(G)$ ve katılaştırma hızının $(V)$ birbirinden bağımsız olarak kontrol edilebildiği süreçtir. Katılaştırma parametrelerine $\left(C_{o}, G, V\right)$ bağlı olarak, malzemelerin mikroyap1 değerleri (ötektik mesafe, lameller arası mesafe veya lamelsel mesafe, dendiritler arası mesafe) ve buna bağlı olarak da malzemelerin mekanik, elektriksel ve 1sısal özellikleri değişmektedir (Engin, 2013).

Katılaştırma parametrelerinin malzemenin mikroyapısı üzerindeki etkin sonucunu belirlemek amacıyla birçok araştırmacı tarafından çeşitli deneysel çalışmalar yapılmıştır ve yapılmaya devam etmektedir (Engin, 2013; Min vd., 2015; Miller ve Pollock, 2014; Du vd., 2014; Li vd., 2006; Paliwal ve Jung, 2013; Walker vd., 2007; Kaya vd., 2009; Jones, 2005; Çadırlı vd., 1999; Li vd., 2007). Bu çalışmaların pek çoğunda sicaklık gradyentinin veya katılaştırma hızının birbirinden bağımsız olarak kontrol edilebilmesi nedeniyle Bridgman Tipi Katılaştırma Fırını kullanılmaktadır (Engin 2013, Min vd., 2015; Miller ve Pollock, 2014; Du vd., 2014; Li vd., 2006; Paliwal ve Jung, 2013; Walker vd., 2007; Kaya vd., 2009; Jones 2005; Çadırlı vd., 1999; Li vd., 2007).

$\mathrm{Bu}$ yöntem, özellikle otomotiv ve uçak sanayinde kullanılan metalik alaşımlar için, istenilen bileşimlerde hazırlanan numunelerde değişken sıcaklık gradyentinde ve katılaştırma hızlarında kontrollü katılaştırma yapılarak alaşımların mikroyapısına bağlı olarak mekanik özelliklerindeki değişimi inceleyebileceğimiz güvenilir yöntemlerden biridir.

Alüminyum ve alüminyum alaşımları, özgül ağırlığının düşük olması, elektrĭgi ve 1sıyı iyi iletmesi ve kolay biçimlendirilebilirlik gibi özelliklerinden dolayı günümüz endüstrisinde son yıllarda artan kullanım alanına sahip malzemeler konumuna gelmişlerdir. Alüminyum ve alüminyum alaşımları için her geçen gün yeni kullanım alanları açılmakta olup bu kullanım alanları; ev eşyalarından uzay teknolojisine kadar geniş bir alana yayılmıştır. Bununla birlikte saf alüminyum ve alüminyum alaşımlarının düşük mukavemeti ve kararsız mekanik özellikleri gibi problemleri de baş göstermektedir (Rana vd., 2012).

$\mathrm{Bu}$ çalışmada, bu tür problemlerin üstesinden gelebilmek için, mekanik, fiziksel ve tribolojik kombinasyonlarından dolayı endüstride temel alaşımlar arasında kabul edilen $\mathrm{Al}-\mathrm{Cu}$ alaşımı (Jones 2005; Çadırlı vd.,1999; Li vd., 2007; Rana vd., 2012; Das vd., 2008) seçilerek Bridgman tipi firın vasıtasıyla sabit sıcaklık gradyentinde beş farklı hızda kontrollü doğrusal katılaştırılma deneyleri yapılmıştır. Özellikle $\mathrm{Al}-\mathrm{Cu}$ alaşımı mukavemetinin iyi olması nedeniyle otomotiv sanayinde gövde elemanı olarak kullanılır ve alüminyum içine katkılanan bakır elementi alaşımı gevrekleştirmeden dayanımını artırdığı için yine otomotiv sanayinde zora dayanıklı parçaların yapımında tercih edilmektedir. $\mathrm{Bu}$ nedenle bu çalışma kapsamında $\mathrm{Al}-\mathrm{Cu}$ alaşımın mekanik özelliklerinin ve elektriksel özdirenç değerinin katılaştırma koşullarına bağlılığını net bir şekilde belirleyebilmek için ötektik komposizyon tercih edilmiştir. Çünkü ötektik alaşım, alaşımı oluşturan elementlerin erime noktasından daha düşük erime sıcaklığına sahip olup, bu bileşimde alaşımın akıcılığının çok yüksek olmasının yanı sıra, tek bir sıvı fazdan iki ayrı faz elde edilmesi nedeniyle endüstriyel uygulama alanlarına sahiptir ve mikroyapının en düzenli bulunduğu durumdadır. Yapılan deneyler neticesinde $\mathrm{Al}-\% 33 \mathrm{ağ}$. $\mathrm{Cu}$ ötektik alaşımının mikroyapı $(\lambda)$, mikrosertlik $(H V)$, çekme dayanım $\left(\sigma_{u t s}\right)$ ve elektriksel özdirenç $(\rho)$ değerlerinin katılaştırma hızına bağlı olarak değişimi bir bütün halinde belirlenmiştir. Ayrıca deneysel veriler arasındaki ilişki hem lineer regrasyon analizi kullanılarak hem de Hall-Petch tipi bağıntılarla ortaya çıkarılmış ve benzer deneysel çalışmalarla kıyaslanmıştır. 


\section{Deneysel Süreç}

\subsection{Alaşımın Hazırlanması Doğrusal Katılaştırma ve Metalografi}

Faz diyagramından elde edilen $\mathrm{Al}-\% 33 \mathrm{ağ} . \mathrm{Cu}$ ötektik bileşimi için stokiyometrik hesaplamalar yapılarak elementlerin miktarları belirlendi. Miktarı belirlenen \%99.99 saflıklardaki alüminyum ve bakır elementleri hassas terazi ile tartıldıktan sonra sirayla vakumlu eritme firını içindeki grafit potaya yerleştirildi. Fırın içinde alüminyum ve bakır elementlerinin vakumlanarak oksitlenmeden eritilmesi sağlandıktan sonra belirli aralıklarla grafit çubuk yardımıyla karıştırılarak alaşımın homojen hale gelmesi sağlandı. Döküm firını içindeki grafitten yapılmış $200 \mathrm{~mm}$ uzunluğunda $4 \mathrm{~mm}$ iç çapa ve $6.35 \mathrm{~mm}$ diş çapa sahip 10 adet silindir şeklindeki numune kalıpları içine homojen hale getirilen alaşımın dökümü yapıldı. Döküm firını yardımıyla eriyik haldeki alaşımın özel numune kalıpları içerisine dökümünün yapılması ve alaşımın kalıpların içerisinde alttan üste doğru kontrolsüz katılaştırılarak numune kalıbının içinde hava boşluğu kalmasına izin verilmeden tamamen doldurulması sağlandı. Hazırlanan numune kalıplarının her biri sabit sicaklık gradyentinde $(\mathrm{G}$ $=8.50 \mathrm{~K} / \mathrm{mm})$ beş farklı katılaştırma hızında $(\mathrm{V}=$ $8.25-164.80 \mu \mathrm{m} / \mathrm{s})$ tek yönlü kontrollü katılaştırılmak üzere Şekil 1'de şematik gösterimi verilen Bridgman tipi firın içine yerleştirildi. Bridman tipi firın içindeki numune üzerinde sabit sıcaklık gradyentini sağlayabilmek için yeterli süre beklenildikten sonra kontrollü katılaştırmayı gerçekleştirmek üzere sekronize motorlar vasıtasıyla her bir numune ayrı ayrı Şekil 1b'de tanımlanan sicak bölgeden soğuk bölgeye doğru çekildi.

Her bir numunenin yaklaşık 100-120 mm kontrollü katılaşması sağlandıktan sonra numuneler senkronize motordan bağımsız olarak çok hızlı bir şekilde soğuk bölgeye çekilerek hızlı soğutma (quench) işlemi gerçekleştirildi. Kontrollü katılaştırma deneyleri tamamlanan her bir numunenin 10-12 mm uzunluğunda kat1-sıv1 arayüzeyine en yakın kısımları kesilerek epoxy-resin ile kalıplandi. Numunelerin mikroskop altında mikroyapılarını tayin edebilmek ve fotoğraflarını alabilmek için sirasiyla Struers TegraPol-15 cihazindan faydalanılarak zımparalama ve parlatma metalografik işlemleri yapıldı. Numuneler üzerindeki mikroyapıları tam olarak ortaya çıkarabilmek için ise $5 \mathrm{ml}$ hidroflorik asit $+95 \mathrm{ml}$ su ile hazırlanan çözeltiyle 10-15 saniye kadar dağlandı.

\subsection{Katılaştırma Parametrelerinin Ölçümü ve Mikroyapının Gözlenmesi}

Numunelerin Bridgman tipi firınında katılaştırma işlemine geçilmeden önce $\mathrm{K}$-tipi $0.25 \mathrm{~mm}$ çapındaki üç termal çift numune içine $10 \mathrm{~mm}$ aralıklarla yerleștirilerek deney süresince numune üzerindeki sıcaklık gradyenti ve katılaştırma hızları belirlendi (Şekil 1c). Sıvı fazın sıcaklık gradyenti $(\mathrm{G}=\Delta \mathrm{T} / \Delta \mathrm{X})$ ve kat1-sıv1 arayüzeyinin katılaştırma hızı $(\mathrm{V}=\Delta \mathrm{X} / \Delta \mathrm{t})$ her bir numune için $\Delta \mathrm{T}, \Delta \mathrm{X}$ ve $\Delta \mathrm{t}$ değerlerinin belirlenmesiyle hesaplandı. $\Delta \mathrm{T}, \Delta \mathrm{X}$ ve $\Delta \mathrm{t}$ değerleri sirasiyla termalçiftlerin ölçtüğü sıcaklık, termalçiftler arası mesafe ve kat1-sıv1 arayüzeyinin iki termal çift aralığını tamamlama süresidir. Katılaştırma parametrelerinin ölçümünlerinin ayrıntılı bilgisi Engin (2013) ve Böyük (2009)'de verilmektedir.

Bridgman firınında kontrollü doğrusal katılaştırmaları yapılan ve metalografi işlemleri tamamlanan her bir numunenin hem enine hem de boyuna kesitlerinden $\boldsymbol{L E} \boldsymbol{O}$ model SEM (Scanning Electron Microscope) cihaziyla fotoğraflanarak mikroyapıları belirlendi. Mikroskop altında ötektik bir mikroyapıya sahip olduğu belirlenen numunelerde gözlemlenen her bir fazı belirlemek için ise EDX (Energy Dispersive $\mathrm{X}$-Ray) analizleri yapıldı (Şekil 2). Her bir numune için farklı büyütme oranlarında çekilen fotoğraflardan Image ProPlus programı yardımıla yan yana dizilen düzenli yapılardan tekrar eden fazların toplam genişliği olarak tanımlanan ötektik mesafeler $(\lambda)$ Şekil 3'te gösterildiği gibi ölçüldü. $\mathrm{Bu}$ yöntem "linear intercept" metodu olarak tanımlanır (Ourdjini vd., 1994) ve ölçme işlemi en az $30 \mathrm{kez}$ tekrarlanıp ortalama değer alınarak ölçümün güvenilirliği sağlandı.

\subsection{Mikrosertlik ve Çekme Dayanım Değerinin Ölçülmesi}

$\mathrm{Bu}$ çalışmanın amaçlarından biri de katılaştırma hızına bağlı olarak değişen mikroyapının mekanik özelliklere etkisini ortaya koymaktır. Bu nedenle ötektik bileşimde hazırlanan $\mathrm{Al}-\mathrm{Cu}$ alaşımının kontrollü katılaştırılması ve metalografi işlemleri yapıldiktan sonra Future-Tech FM-700 model Vickers sertlik ölçüm cihazı kullanılarak numune üzerine 500 g'lık yükün $10 \mathrm{~s}$ uygulanmasıyla meydana gelen $40-60 \mu \mathrm{m}$ 'lik iz yardımıyla her bir numunenin mikrosertlik değeri belirlendi. 


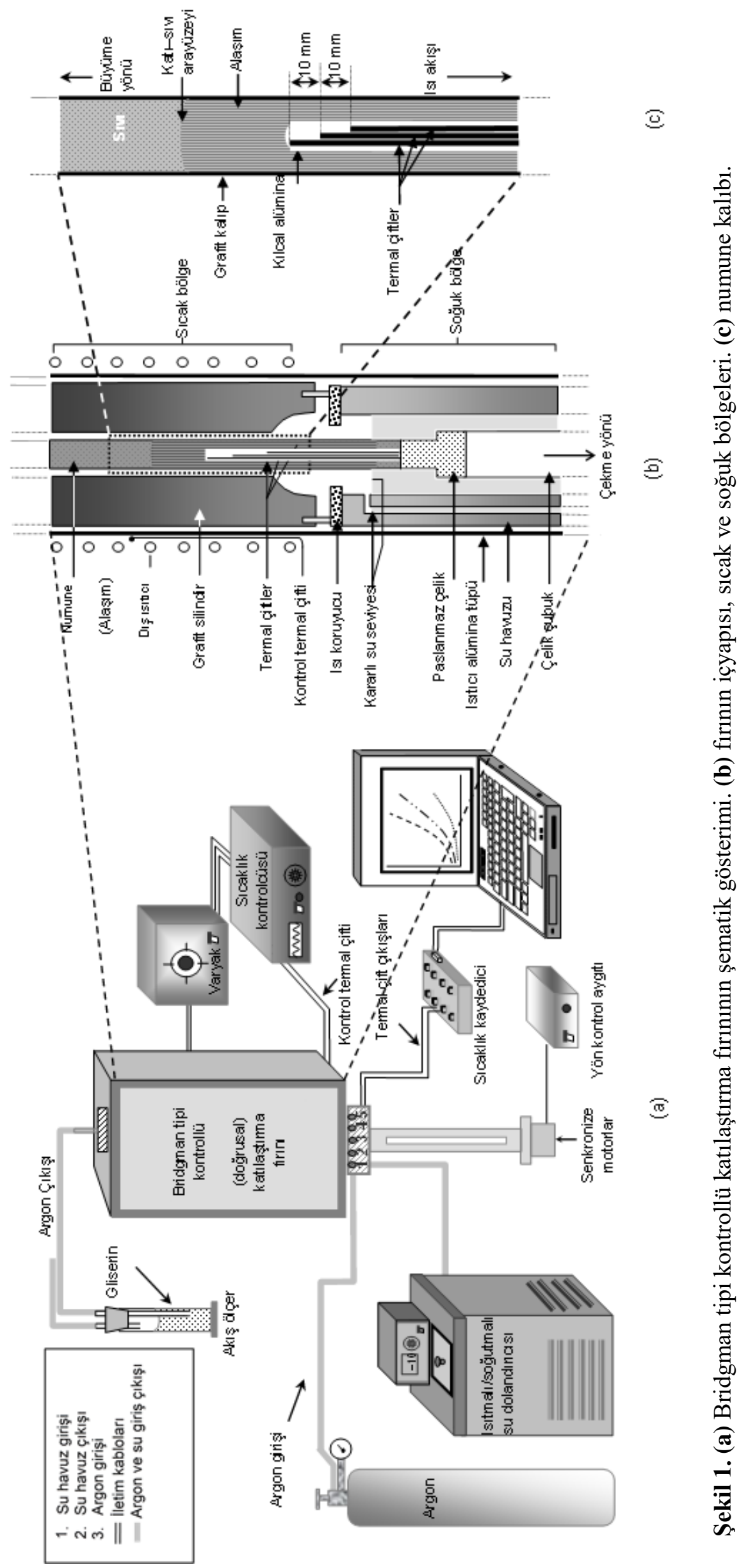




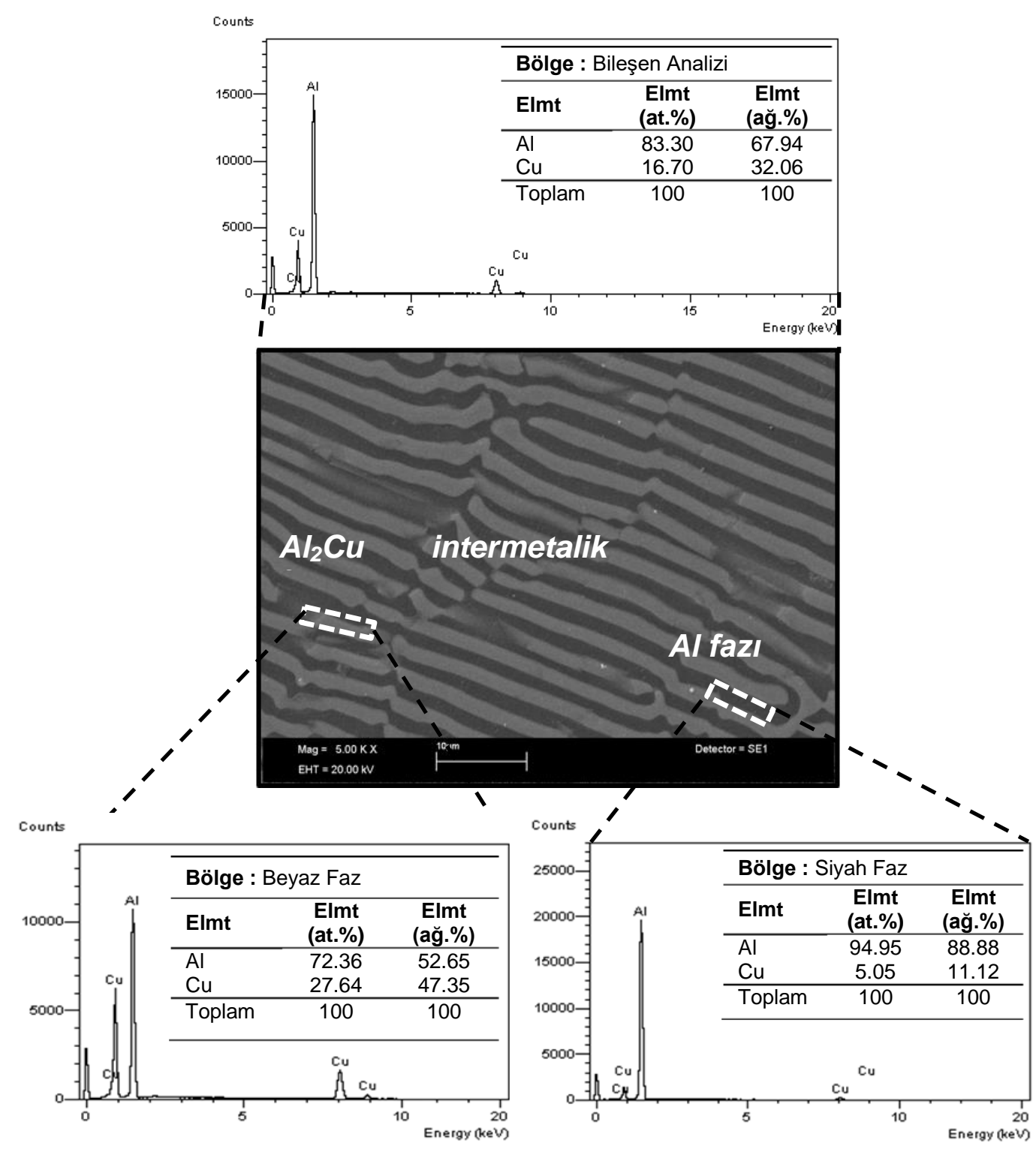

Şekil 2. Al-33Cu ötektik alaşımının kimyasal bileşim analizi $(E D X)$, ana faz, beyaz ve siyah lamelsel fazlar.

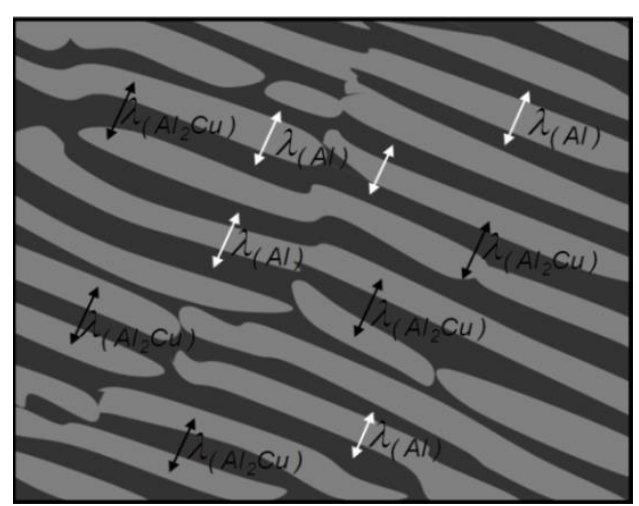

(a)

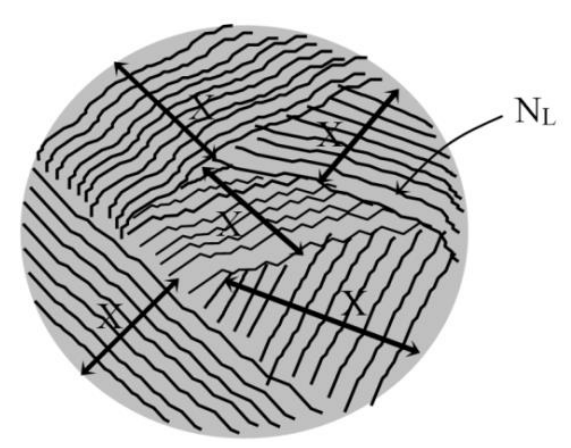

(b)

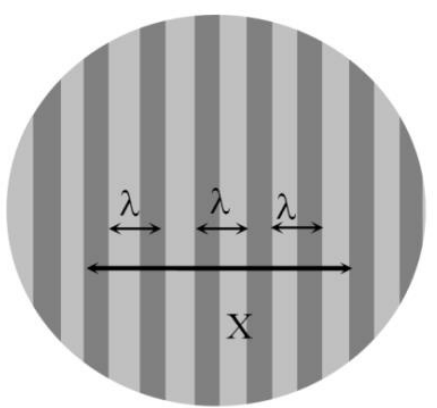

(c)

Şekil 3. (a) Doğrusal katılaştırılmış Al-33Cu ötektik alaşımı için lamelsel mesafelerin ölçümü. (b) şematik geniş bölge görüntüsü. (c) şematik dar bölge görüntüsü (lineer intercept metodu: $\lambda=X /\left(N_{L}-1\right)$. Burada $X$, lamellerin toplam genişliği, $\mathrm{N}_{\mathrm{L}}$ ise toplam lamel sayısıdır. 
$\mathrm{Bu}$ işlem en az $10 \mathrm{kez}$ tekrarlanıp ortalama değer alınarak ölçümün güvenilirliği sağlandı.

Beş farklı hızda kontrollü doğrusal katılaştırılan ve $4 \mathrm{~mm}$ çapında ve $50 \mathrm{~mm}$ uzunluğunda hazırlanan numuneler için Shimatzu Universal Testing Instrument yardımıyla $10^{-3} \mathrm{~s}$ gerilim uygulanarak maksimum çekme-dayanım değerleri belirlendi. $\mathrm{Bu}$ işlem en az $3 \mathrm{kez}$ tekrarlanıp ortalama değer alınarak ölçümün güvenilirliği sağland.

\subsection{Elektriksel Özdirenç Değerinin Ölçülmesi}

Kontrollü katılaştırmaları yapılan $4 \mathrm{~mm}$ çapında $20 \mathrm{~mm}$ uzunluğundaki her bir numunenin dört nokta uç (four-point) yöntemi kullanılarak elektriksel özdirenç değerleri ölçüldü. $\mathrm{Bu}$ yöntemin kullanımı ve ölçümü ile ilgili ayrıntılı bilgisi Smiths (1958)'de verilmektedir. $0.5 \mathrm{~mm}$ çapındaki 4 adet platin tel vasıtasıyla numune üzerine uygulanan akıma karşı voltaj değerinin ölçülerek elektriksel özdirenç değerinin belirlenmesi esasına dayanan bir yöntemdir. Elektriksel özdirenç değerinin belirlenmesi için aynı numene üzerinden 50 ölçüm yapılarak ortalama değer alınıp sonucun güvenilirliği sağlandı.

\section{Sonuç ve Tartışmalar}

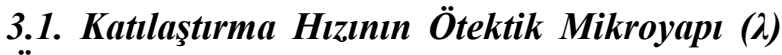 Üzerine Etkisi}

Şekil 3-4'te gösterildiği gibi Al-\%33ağ. Cu ötektik alaşımı ana (matrix) Al ve beyaz lamelsel $\mathrm{Al}_{2} \mathrm{Cu}$ intermetalik fazların düzenli siralandığ 1 mikroyapıya sahip olduğu gözlendi. $\mathrm{Bu}$ tür düzenli bir yapı için her iki fazın da katı-sıvı arayüzey yakınlarında düşük entropiye sahip olması ve çekirdeklenme başladıktan sonra çok az bir alt soğuma yardımıyla her iki fazın eş zamanlı büyümesini gerektirir. Katılaşma süresince katısıv1 arayüzeyi önündeki sıvı faz içinde oluşan sicakl1k gradyenti ise kristaller boyunca oluşan mikroyapının korunmasını ya da sürekliliğini sağlar (Hecht vd., 2004; Çadırlı vd., 1999).

Yapılan kontrollü katılaştırma deneyleri neticesinde Şekil 4'te de görüldüğü gibi katılaştırma hızı arttıkça lameller arası mesafe $\lambda$ değerinin azaldığ sınırlarının ortaya çıktığı ve bu sınır etrafında lamellerin kalınlaşarak düzensiz hale geldikleri görülmektedir.
Şekil 4. Doğrusal katılaştırılmış Al-33Cu ötektik alaşımı için sabit sicaklık gradyenti $(\mathrm{G}=8.50$ $\mathrm{K} / \mathrm{mm}$ ) farklı katılaştırma hizlarında (V=8.25-164.80 $\mu \mathrm{m} / \mathrm{s}$ ) oluşan mikroyapıların bazı enine kesit SEM fotoğrafları (a) - (b) V=8.25 $\mu \mathrm{m} / \mathrm{s}$, (c) - (d) $\mathrm{V}=41.65 \mu \mathrm{m} / \mathrm{s}$, (e) - (f) $V=164.80 \mu \mathrm{m} / \mathrm{s}$.

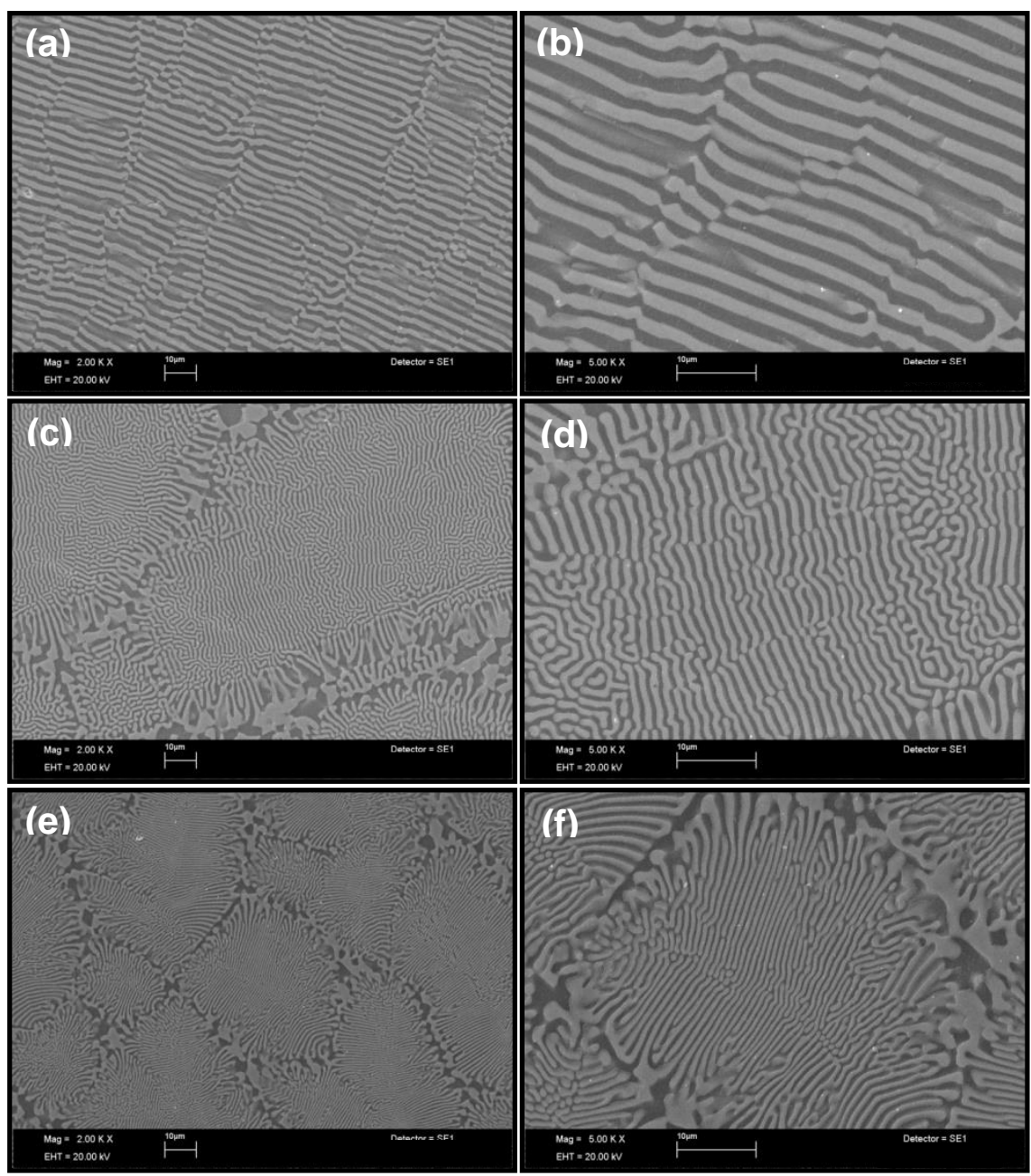


$\mathrm{Bu}$ nedenle yüksek hızlarda lameller arası mesafe ölçümleri tanelerin içindeki düzenli bölgelerden yapıldı. En büyük mikroyap1 değeri en düşük katılaştırma hızında $(\mathrm{V}=8.25 \mu \mathrm{m} / \mathrm{s})$ ve en küçük mikroyapı değeri ise en yüksek katılaştırma hizında (V $=164.80 \mu \mathrm{m} / \mathrm{s})$ elde edildi. Elde edilen sonuçlar neticesinde mikroyapı ve katılaştırma hızı arasındaki ilişkiyi tam olarak ortaya çıkarabilmek için lineer regrasyon analizinden faydalanıldı. Şekil 5 'te belirtildiği gibi mikroyapı ve katılaştırma hızını ifade eden lineer regrasyon analizi;

$\lambda=k_{1} V^{-n_{1}}$

şeklinde tanımlanır. Burada $\mathrm{k}_{1}$ denklem sabiti (SigmaPlot 11 programı yardımıyla çizdirilen lineer regrasyon grafiğinin eğimini ifade eder), $\mathrm{n}_{1}$ ise katılaştırma hızının üstel değeridir. Mikroyapı için elde edilen ölçüm sonuçları Tablo 1'de verilmiştir. Elde edilen sonuçlarda dikkat edilmesi gereken husus oluşturulan logaritmik grafik vasitasiyla elde edilen $\mathrm{n}_{1}$ üstel değeri olup Jacson-Hunt teorik modeline göre düzenli mikroyapı gözlenen alaşımlar için bu değerin 0.50 olmas1 gerekmektedir (Jackson ve Hunt, 1966).
Al-Cu ötektik alaşımı için bu değer Jacson-Hunt teorik modeline oldukça yakın değer olan 0.54 olarak hesaplandi. Elde edilen bu değer literatürdeki Al esaslı benzer çalışmalarla kıyaslandığında Kaya vd. (2010) tarafindan yapılan $\mathrm{Al}-\mathrm{Ni}$ ötektik alaşımı için elde edilen değer 0.50 değeri ve Gündüz vd. (2004) tarafından yapılan Al-Si ötektik alaşımı için elde edilen 0.46 değerleriyle de uyum içindedir.

Fakat bu çalışmada elde edilen değer Çadırlı vd. (1999) tarafindan yapılan $\mathrm{Al}-\mathrm{Cu}$ alaşımı, Kaya vd. (2013) tarafindan yapılan Al-Ni alaşımı ve Goulart vd. (2006), Peres vd. (2004) tarafindan yapılan Al-Si alaşımları için elde edilen sırasıyla $0.400 .26,(2 / 3)$ ve $(2 / 3)$ değerlerinden oldukça farklıdır. Çünkü elde edilmesi gereken 0.50 değeri düzenli ötektik yapılar için belirlenmiş teorik sonuç olup, dendiritik mikroyapı ve düzensiz ötektik mikroyapılar için geçerli değildir. Özellikle Goulart vd. (2006) tarafindan elde edilen değerler için $\mathrm{Al}-\mathrm{Si}$ alaşımının ötektik bileşende hazırlanmadığ mikroyapıların dendiritik elde edilmesi nedeniyle teorik modelden saptığını net bir şekilde söyleyebiliriz.

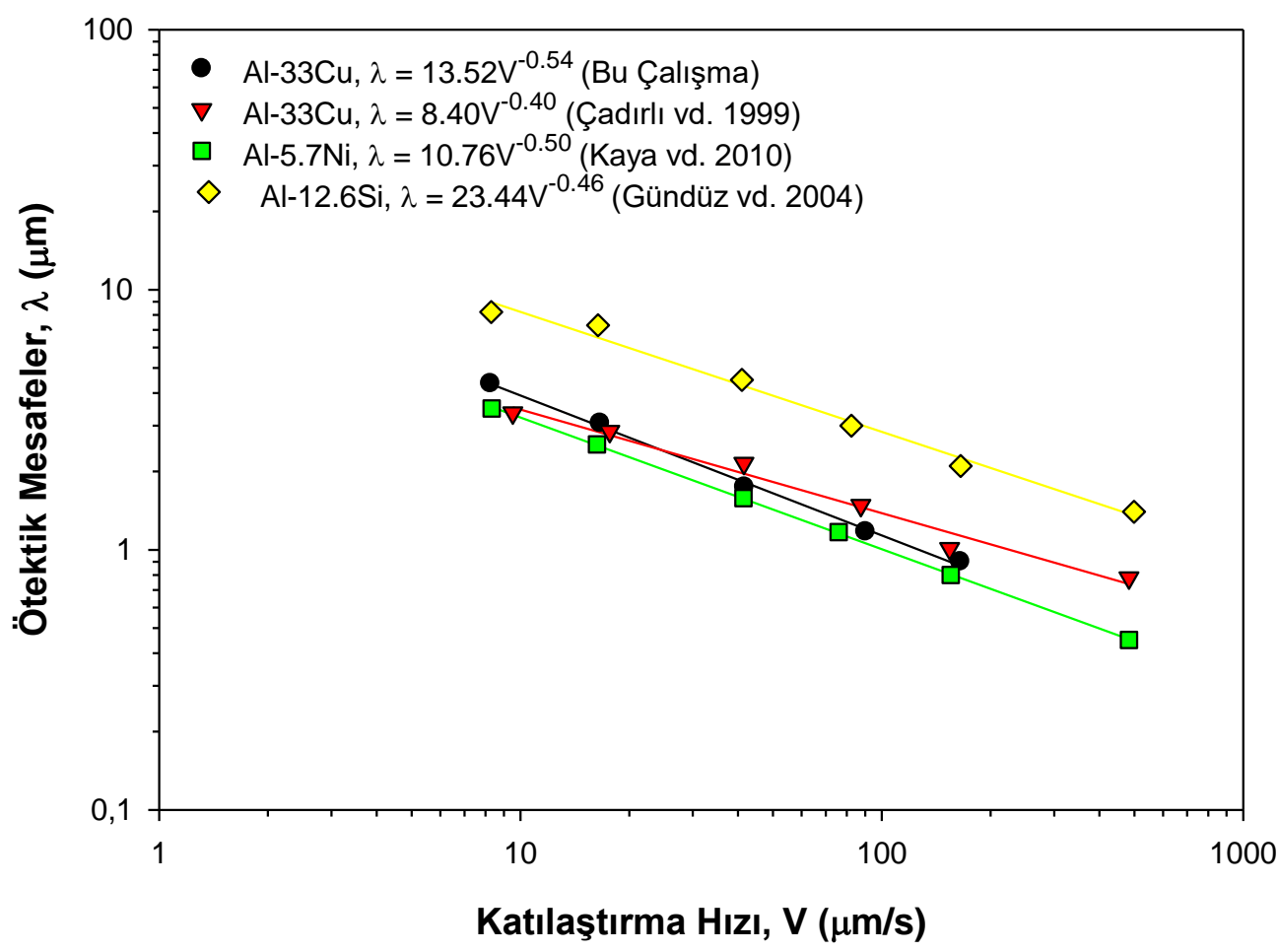

Şekil 5. Doğrusal katılaştırılmış Al-33Cu ötektik alaşımı için ötektik mesafelerin katılaştırma hızı ile değişimi ve lineer regrasyon bağıntısı ve literatürdeki benzer çalışmalarla kıyaslanması. 
Tablo 1. Al-33Cu alaşımı için elde edilen ötektik mesafeler, mikrosertlik, çekme-dayanım ve elektriksel özdirenç değerleri.

\begin{tabular}{|c|c|c|c|c|c|c|}
\hline $\begin{array}{l}\text { Alaşım } \\
\text { (\% ağ.) }\end{array}$ & Katılaştırma & metreleri & $\begin{array}{c}\text { Ötektik } \\
\text { Mesafeler }\end{array}$ & Mikrosertlik & $\begin{array}{c}\text { Maksimum Çekme- } \\
\text { Dayanım }\end{array}$ & $\begin{array}{c}\text { Elektriksel } \\
\text { Özdirenç }\end{array}$ \\
\hline \multirow{6}{*}{$\mathrm{Al}-33 \mathrm{Cu}$} & $\begin{array}{c}\mathbf{G} \\
(\mathbf{K} / \mathbf{m m})\end{array}$ & $\begin{array}{c}\mathrm{V} \\
(\mu \mathrm{m} / \mathrm{s})\end{array}$ & $\begin{array}{c}\lambda \\
(\mu \mathrm{m})\end{array}$ & $\begin{array}{c}\mathrm{HV} \\
\left(\mathbf{k g} / \mathbf{m m}^{2}\right)\end{array}$ & $\begin{array}{c}\sigma_{\mathrm{uts}} \\
\left(\mathbf{N} / \mathbf{m m}^{2}\right)\end{array}$ & $\begin{array}{c}\rho \times 10^{-8} \\
(\Omega \mathrm{m})\end{array}$ \\
\hline & \multirow{5}{*}{8.50} & 8.25 & 4.36 & 143.48 & 45.62 & 4.13 \\
\hline & & 16.60 & 3.07 & 155.96 & 46.05 & 4.56 \\
\hline & & 41.65 & 1.74 & 162.96 & 52.63 & 4.85 \\
\hline & & 90.05 & 1.17 & 175.88 & 57.42 & 5.40 \\
\hline & & 164.80 & 0.90 & 185.19 & 59.16 & 6.04 \\
\hline
\end{tabular}

\subsection{Katılaştırma Hızının Mikrosertlik ve Çekme-Dayanım Üzerine Etkisi}

Şekil 6 ve Şekil 7'de katılaştırma hızı artıkça mikrosertlik ve çekme-dayanım değerlerinin de arttığ1 görülmektedir. Mikrosertlik değerinin, mikroyapı ve katılaştırma hızı ile aralarındaki ilişkiyi ortaya çıkarmak için kullanılan lineer regranyon analizleri;

$$
\begin{aligned}
& H V=k_{2} V^{-n_{2}} \\
& H V=k_{3} \lambda^{n_{3}}
\end{aligned}
$$

ve çekme-dayanım değerinin, mikroyapı ve katılaştırma hızı ile aralarındaki ilişkiyi ortaya çıkarmak için kullanılan lineer regranyon analizleri;

$$
\begin{aligned}
& \sigma_{u t s}=k_{4} V^{-n_{4}} \\
& \sigma_{u t s}=k_{5} \lambda^{n_{5}}
\end{aligned}
$$

şeklinde tanımlanmaktadır. Burada $\mathrm{k}_{2}, \mathrm{k}_{3}, \mathrm{k}_{4}$ ve $\mathrm{k}_{5}$ denklem sabitleri, $\mathrm{n}_{2}, \mathrm{n}_{3}, \mathrm{n}_{4}$ ve $\mathrm{n}_{5}$ ise mikroyap1 ve katılaştırma hızının üstel değerleridir.
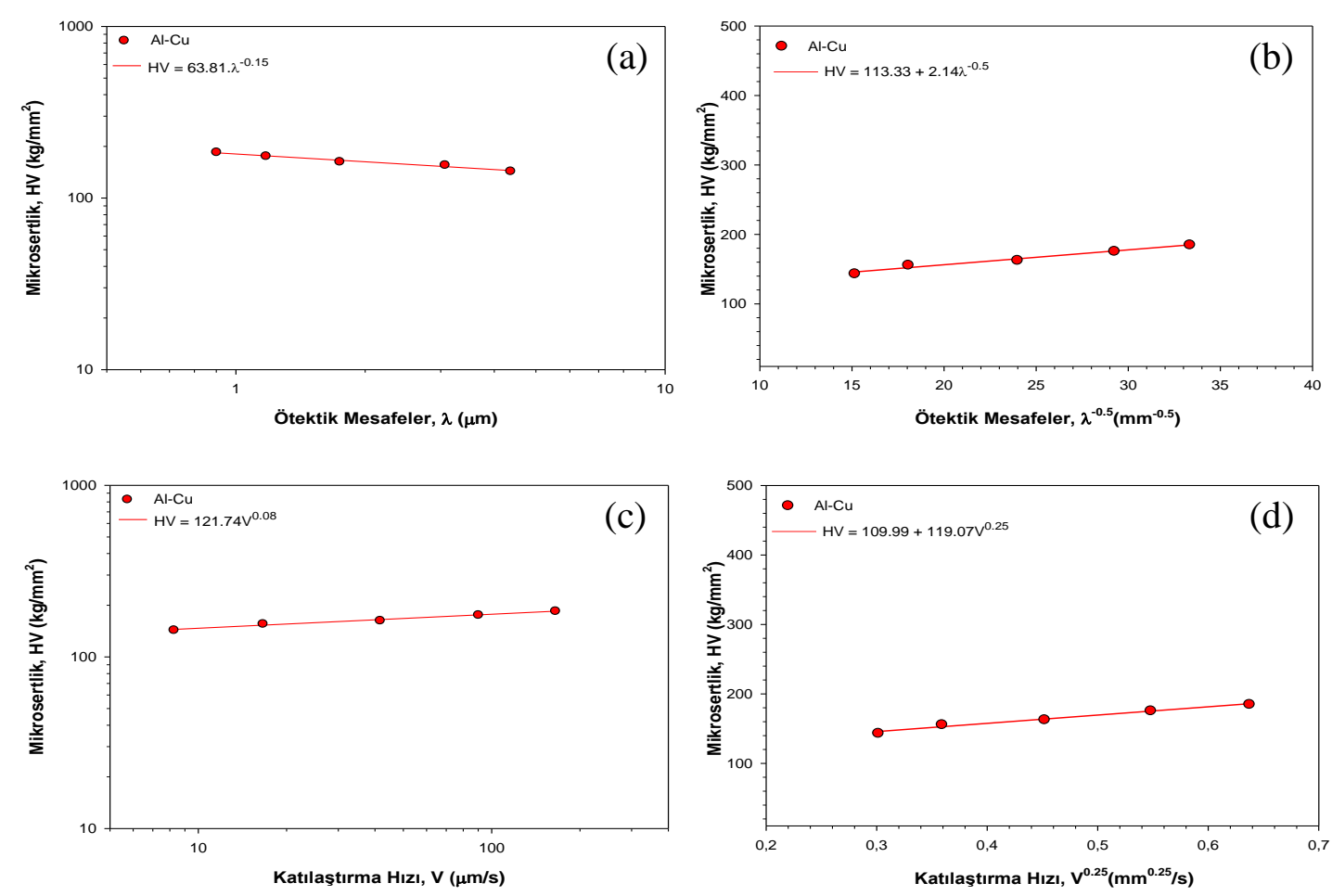

Şekil 6. Doğrusal katılaştırılmış Al-33Cu ötektik alaşımı için; (a) mikrosertlik değerlerinin mikroyapı ile değişimi ve lineer regrasyon bağıntısı. (b) mikrosertlik değerlerinin mikroyapı ile değişimi ve Hall-Petch tipi bağıntısı. (c) mikrosertlik değerlerinin katılaştırma hızı ile değişimi ve lineer regrasyon bağıntısı. (d) mikrosertlik değerlerinin katılaştırma hızı ile değişimi ve Hall-Petch tipi bağıntısı. 

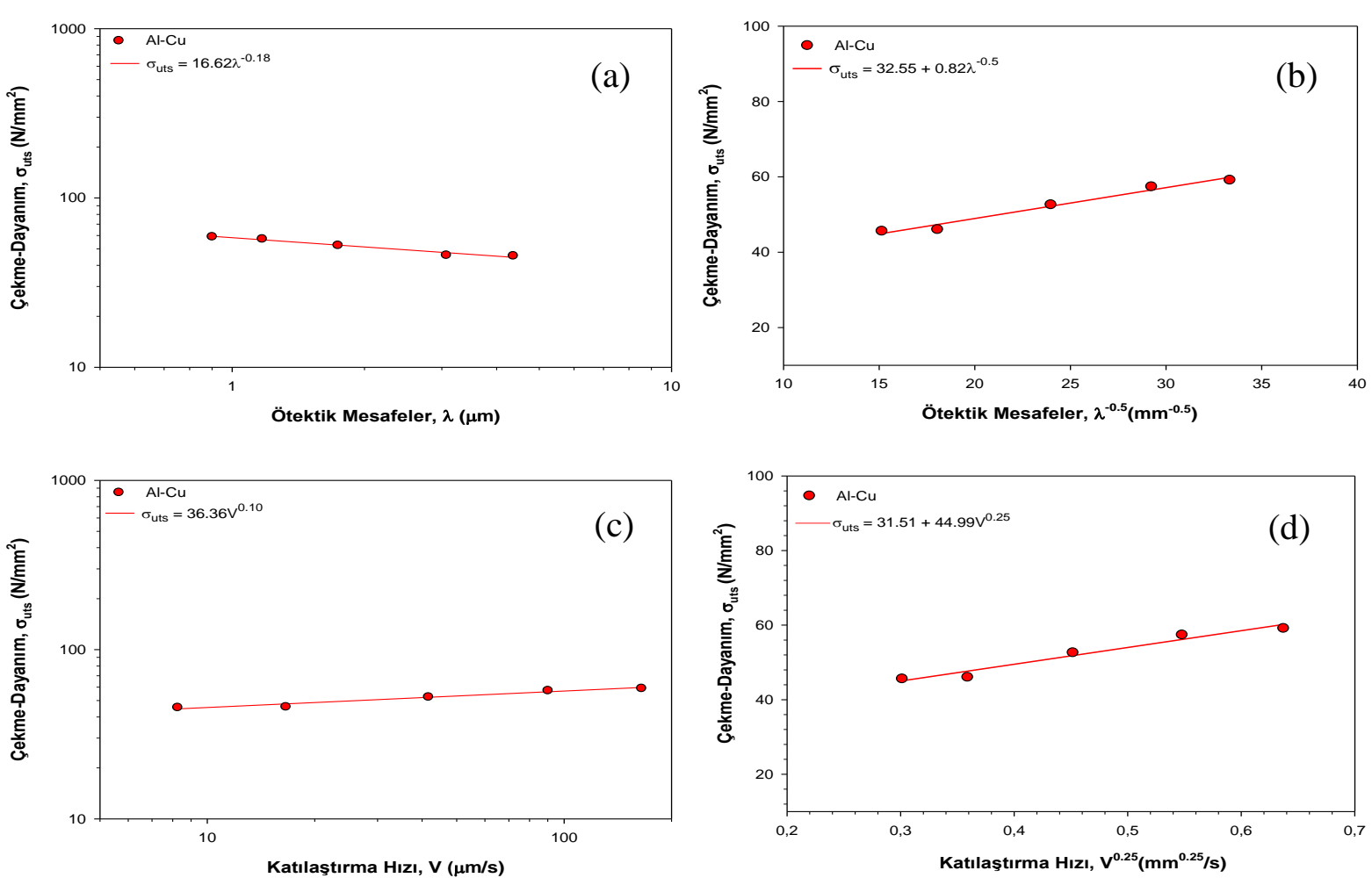

Şekil 7. Doğrusal katılaştırılmış Al-33Cu ötektik alaşımı için; (a) çekme-dayanım değerlerinin mikroyapı ile değişimi ve lineer regrasyon bağıntısı. (b) çekme-dayanım değerlerinin mikroyapı ile değişimi ve HallPetch tipi bağıntısı. (c) çekme-dayanım değerlerinin katılaştırma hızı ile değişimi ve lineer regrasyon bağıntısı. (d) çekme-dayanım değerlerinin katılaştırma hızı ile değişimi ve Hall-Petch tipi bağıntısı.

Tablo 2'de verilen değerlerden de anlaşıldığı üzere katılaştırma hızı ile mikrosertlik değeri arasındaki ilişkiyi veren lineer regrasyon analizi ile elde edilen üstel değerler 0.05 ve 0.11 aralığındadır (Kaya vd., 2013; Kaya vd., 2012; Kaya vd., 2003; Kaya vd., 2009). Bu çalışmada katılaştırma hızı için elde edilen üstel değer Şekil 5 'te verildiği gibi 0.08 olup yapılan benzer çalışmalarla uyum içerisindedir. Benzer şekilde mikroyap1 ile mikrosertlik değeri arasındaki ilişkiyi veren lineer regrasyon analizi ile elde edilen üstel değerler 0.23 ve 0.30 aralı̆̆ındadır (Kaya vd., 2012; Kaya vd., 2003; Kaya vd., 2009). Bu sonuçlardan da görüldügü üzere yapılan çalışmalarda yaklaşık aynı katılaştırma hızları kullanılsa da elde edilen mikroyapı alaşımın bileşimine göre (ötektik ötektik altı ve ötektik üstü gibi) ve ortaya çıan mikroyapı özelliğine göre (lamelsel, çubuksal, hücresel, flake gibi) değiştiği için elde edilen değerler birbirlerinden oldukça farklı olmuştur.

Mikrosertlik sonuçlarına benzer sonuçlar çekmedayanım değeri için de görülmektedir. Son yıllarda mekanik özelliklerin incelemesi başlığı altında mikrosertliğin yanı sıra çekme-dayanım özelliklerine de yer verilmektedir. Çekmedayanım değerinin de katılaşma hızı arttıkça arttığ Şekil 6'da net bir şekilde görülmektedir. Çekme-dayanım ve katılaştırma hızı arasındaki ilişkiyi belirlemek için kullanılan lineer regrasyon analizine göre üstel değer 0.10 ve çekme-dayanım ve mikroyapı arasındaki ilişkiyi belirlemek için kullanılan lineer regrasyon analizine göre üstel değer ifadesi 0.18 olarak elde edilmiştir. Fakat bu konuda yapılan çalışmalarda daha çok Hall-Petch tipi bağıntı tercih edilmesi nedeniyle sonuçlar lineer regrasyon analiziyle yapılanlarla kıyaslanamamıştır.

Mikroyapı ve katılaştırma hızı ile mikrosertlik değerleri arasındaki ilişkiyi tanımlayan bir başka analiz ise Hall-Petch tipi bağıntılardır. Mikrosertlik değerinin mikroyapı ve katılaştırma hızı ile aralarındaki ilişkiyi ortaya koyan HallPetch tipi bağıntılar;

$$
\begin{aligned}
& H V=H V_{o}+k_{6} V^{0.25} \\
& H V=H V_{o}+k_{7} \lambda^{-0.50}
\end{aligned}
$$


ve çekme-dayanım değerinin mikroyapı ve katılaştırma hızı ile aralarındaki ilişkiyi ortaya koyan Hall-Petch tipi bağıntılar;

$$
\begin{aligned}
& \sigma_{u t s}=\sigma_{u t s_{o}}+k_{8} V^{0.25} \\
& \sigma_{u t s}=\sigma_{u t s_{o}}+k_{9} V^{-0.50}
\end{aligned}
$$

şeklinde tanımlanır. Burada $\boldsymbol{H V}_{\boldsymbol{o}}$ erime sıcaklığındaki sıvı faz ile dengede bulunan katı fazın başlangıç mikrosertlik değeri, benzer şekilde $\boldsymbol{\sigma}_{\boldsymbol{u} \boldsymbol{u s}_{\boldsymbol{o}}}$ erime sicaklığındaki sıvı faz ile dengede bulunan katı fazın başlangıç çekme-dayanım değeri ve $\mathrm{k}_{6}, \mathrm{k}_{7}, \mathrm{k}_{8}$ ve $\mathrm{k}_{9}$ denklem sabitleridir.

Mikroyap1, katılaştırma hızı, mikrosertlik ve çekme-dayanım değerleri aralarındaki ilişkiyi Hall-Petch tipi bağıntılar da net bir şekilde ortaya koymaktadır. Tablo 2'de verilen bu çalışmada elde edilen mikroyapı ve katılaştırma hızı ile mikrosertlik arasındaki ilişkiyi tanımlamamıza yarayan sırasıyla 113.33 ve 109.99 değerleri Kaya vd. (2012) tarafından Al-Ni ötektik alaşımı için elde edilen 31.58 ve 29.39 ve Kaya vd. (2003) tarafindan $\mathrm{Al}-\mathrm{Si}$ ötektik alaşımı için elde edilen 47.16 değerlerinden oldukça büyüktür. Benzer şekilde Silva vd. (2011) tarafindan Al-Ni ve AlFe (Silva vd., 2012) alaşımları için elde edilen sırasıyla $27,44.8$ ve 31 değerleri de bu çalışmada elde edilen 113.33 ve 109.99 değerlerinden küçüktür. Bu çalışmadaki $\mathrm{Cu}$ elementinin alaşımın bileşimindeki oranının $\mathrm{Al}-\mathrm{Ni}, \mathrm{Al}-\mathrm{Si}$ ve $\mathrm{Al}-\mathrm{Fe}$ için yapılan çalışmalardaki bileşimlerindeki Ni, $\mathrm{Si}$ ve Fe elementlerine göre daha fazla orana sahip olmasının da etkisiyle alüminyum esaslı alaşımların mikrosertliğini $\mathrm{Cu}$ elementinin $\mathrm{Ni}, \mathrm{Si}$ ve $\mathrm{Fe}$ elementlerine göre çok daha fazla etkilediği görülmektedir.

Tablo 2'de verilen katılaştırma hızı ve çekmedayanım değerleri aralarındaki ilişkiyi tanımlamamıza yarayan 31.51 ve 32.55 değerleri Cante vd. (2010) tarafindan Al-Ni alaşımı için elde edilen 71.3, 73.2, 74.1 değerlerinden, Goulart vd. (2010) tarafından Al-Fe alaşımı için elde edilen $62.8,60.2,57.6$ değerlerinden ve Goulart vd. (2006) tarafından Al-Si alaşımı için elde edilen 93, 111 değerlerinden, oldukça küçüktür. $\mathrm{Bu}$ çalışmadaki $\mathrm{Cu}$ elementinin $\mathrm{Ni}, \mathrm{Si}$ ve $\mathrm{Fe}$ elementlerine göre alaşımdaki ağırlıkça oranı daha fazla olmasına rağmen çekme-dayanım değerlerini $\mathrm{Ni}, \mathrm{Si}$ ve $\mathrm{Fe}$ elementlerine göre çok etkilemediği görülmektedir.

\subsection{Katılaştırma Hızının Elektriksel Özdirenç Üzerine Etkisi}

Mikroyap1, katılaştırma hızı ve elektriksel özdirenç arasındaki ilişkiyi tanımlayan literatürde çok fazla çalışma yoktur. Genellikle elektriksel özdirenç değerinin sıcaklıkla ilişkisi araştırılmıştır. Mikroyapı, katılaştırma hızı ve elektriksel özdirenç arasındaki ilişkiyi tanımlamak için kullanılan lineer regrasyon analizi;

Tablo 2. Al-\% 33 ağ. Cu ötektik bileşimi için elde edilen sonuçlar ve literatürdeki benzer çalışmaların

\begin{tabular}{|c|c|c|c|c|c|}
\hline $\begin{array}{l}\text { Alaşım } \\
\text { (\%ağ.) }\end{array}$ & Mikroyapı & Mikrosertlik & $\begin{array}{c}\text { Maksimum Çekme- } \\
\text { Dayanım }\end{array}$ & $\begin{array}{c}\text { Elektriksel } \\
\text { Özdirenç }\end{array}$ & Referans \\
\hline $\mathrm{Al}-33 \mathrm{Cu}$ & $\lambda=13.52 V^{-0.54}$ & $\begin{array}{l}H V=63.81 \lambda^{-0.15} \\
H V=113.33+2.14 \lambda^{-0.5} \\
H V=121.74 V^{0.08} \\
H V=109.99+119.07 V^{0.25}\end{array}$ & $\begin{array}{l}\sigma_{u t s}=16.62 \lambda^{-0.18} \\
\sigma_{u t s}=32.55+0.82 \lambda^{-0.5} \\
\sigma_{u t s}=36.36 V^{0.10} \\
\sigma_{u t s}=31.51+44.99 V^{0.25}\end{array}$ & $\begin{array}{l}\rho=0.72 \times 10^{-8} \lambda^{-0.22} \\
\rho=3.19 \times 10^{-8} V^{0.12}\end{array}$ & (Bu çalışma) \\
\hline $\mathrm{Al}-33 \mathrm{Cu}$ & $\lambda=8.40 \mathrm{~V}^{-0.40}$ & & & & (Çadırlı 1999 \\
\hline $\mathrm{Al}-5.7 \mathrm{Ni}$ & $\begin{array}{l}\lambda_{T}=10.76 V^{-0.50} \\
\lambda_{L}=11.61 V^{-0.51}\end{array}$ & & & & (Kaya 2010) \\
\hline Al-5.7Ni & & $\begin{array}{l}H V=66.13 V^{0.10} \\
H V=52.95\left(\lambda_{T}\right)^{-0.23} \\
H V=48.08\left(\lambda_{L}\right)^{-0.20} \\
H V=29.39+41.83 V^{0.25} \\
H V=31.58+0.654(\lambda)^{-0.5} \\
H V=31.25+37.36 V^{0.25}\end{array}$ & & $\begin{array}{l}\rho=1.36 \times 10^{-5} V^{0.07} \\
\rho=4.77 \times 10^{-6}\left(\lambda_{T}\right)^{-0.13}\end{array}$ & (Kaya 2012) \\
\hline Al-7Ni & $\begin{array}{l}\lambda_{1}=851.1 V^{-0.26} \\
\lambda_{2}=124.2 V^{-0.48}\end{array}$ & $\begin{array}{l}H V=66.1 V^{0.11} \\
H V=309.0\left(\lambda_{1}\right)^{-0.35} \\
H V=114.8\left(\lambda_{2}\right)^{-0.24}\end{array}$ & & $\begin{array}{l}\rho=1.4 \times 10^{-5} V^{0.07} \\
\rho=6.9 \times 10^{-6}\left(\lambda_{1}\right)^{-0.22} \\
\rho=6.2 \times 10^{-6}\left(\lambda_{2}\right)^{-0.14}\end{array}$ & (Kaya 2013) \\
\hline $\begin{array}{l}\mathrm{Al}-1 \mathrm{Ni} \\
\mathrm{Al}-3 \mathrm{Ni} \\
\mathrm{Al}-5 \mathrm{Ni}\end{array}$ & & & $\begin{aligned} \sigma_{u t s} & =71.3+200.2\left(\lambda_{1}\right)^{-0.5} \\
\sigma_{u t s} & =52.3+188.3\left(\lambda_{2}\right)^{-0.5} \\
\sigma_{u t s} & =73.2+325.6\left(\lambda_{1}\right)^{-0.5} \\
\sigma_{u t s} & =57.5+221.7\left(\lambda_{2}\right)^{-0.5} \\
\sigma_{u t s} & =74.1+468.5\left(\lambda_{1}\right)^{-0.5} \\
\sigma_{u t s} & =58.3+228.6\left(\lambda_{2}\right)^{-0.5}\end{aligned}$ & & (Cante 2010) \\
\hline
\end{tabular}
sonuçları. 
Tablo 2'nin devamı

\begin{tabular}{|c|c|c|c|c|c|}
\hline $\begin{array}{l}\text { Alaşım } \\
\text { (\%ağ.) }\end{array}$ & Mikroyapı & Mikrosertlik & $\begin{array}{c}\text { Maksimum Çekme- } \\
\text { Dayanım }\end{array}$ & $\begin{array}{l}\text { Elektriksel } \\
\text { Özdirenç }\end{array}$ & Referans \\
\hline $\begin{array}{l}\mathrm{Al}-3 \mathrm{Ni} \\
\mathrm{Al}-5 \mathrm{Ni}\end{array}$ & & $\begin{array}{l}H V=27+104.1(\lambda)^{-0.5} \\
H V=44.8+52.3(\lambda)^{-0.5}\end{array}$ & & & (Silva 2011) \\
\hline $\begin{array}{r}\mathrm{Al}-1 \mathrm{Fe} \\
\mathrm{Al}-1.5 \mathrm{Fe}\end{array}$ & & $\begin{array}{l}H V=31+13.1(\lambda)^{-0.5} \\
H V=31+33.1(\lambda)^{-0.5}\end{array}$ & & & ( Silva 2011) \\
\hline $\begin{array}{l}\mathrm{Al}-1.5 \mathrm{Fe} \\
\mathrm{Al}-1.0 \mathrm{Fe} \\
\mathrm{Al}-0.5 \mathrm{Fe}\end{array}$ & & & $\begin{array}{l}\sigma_{u t s}=62.8+98.3\left(\lambda_{c}\right)^{-0.5} \\
\sigma_{u t s}=60.2+90.5\left(\lambda_{c}\right)^{-0.5} \\
\sigma_{u t s}=57.6+65.4\left(\lambda_{c}\right)^{-0.5}\end{array}$ & & (Goulart 2010) \\
\hline $\mathrm{Al}-12.6 \mathrm{Si}$ & $\lambda=23.44 V^{-0.46}$ & & & & (Gündüz 2004) \\
\hline $\mathrm{Al}-12 \mathrm{Si}$ & & $\begin{array}{l}H V=82.79 V^{0.11} \\
H V=47.16+41.37 V^{0.25}\end{array}$ & & & (Kaya 2012) \\
\hline $\begin{array}{l}\text { Al-5Si } \\
\text { Al-9Si }\end{array}$ & $\lambda_{2}=45 V_{L}^{-2 / 3}$ & & $\begin{array}{l}\sigma_{u t s}=93+45\left(\lambda_{2}\right)^{-0.5} \\
\sigma_{u t s}=111+146\left(\lambda_{2}\right)^{-0.5}\end{array}$ & & (Goulart 2006) \\
\hline $\begin{array}{l}\text { Al-3Si } \\
\text { Al-5Si } \\
\text { Al-7Si } \\
\text { Al-9Si }\end{array}$ & $\begin{array}{l}\lambda_{2}=32 V_{L}^{-2 / 3} \\
\lambda_{2}=32 V_{L}^{-2 / 3} \\
\lambda_{2}=26 V_{L}^{-2 / 3} \\
\lambda_{2}=22 V_{L}^{-2 / 3}\end{array}$ & & & & (Peres 2004) \\
\hline $\begin{array}{l}\mathrm{Al}-0 . \mathrm{TSi} \\
\mathrm{Al}-0.5 \mathrm{Ti} \\
\mathrm{Al}-2 \mathrm{Li}\end{array}$ & & $\begin{array}{l}H V=46.45 V^{0.06} \\
H V=18.28 \lambda^{-0.25} \\
H V=54.95 V^{0.07} \\
H V=18.03 \lambda^{-0.30} \\
H V=37.49 V^{0.05} \\
H V=16.37 \lambda^{-0.24}\end{array}$ & & & (Kaya 2009) \\
\hline
\end{tabular}

$\rho=k_{10} V^{-n_{10}}$

$\rho=k_{11} \lambda^{n_{11}}$

şeklinde tanımlanmaktadır. Burada $\mathrm{k}_{10}$ ve $\mathrm{k}_{11}$ denklem sabitleri, $\mathrm{n}_{10}$ ve $\mathrm{n}_{11}$ ise mikroyap1 ve katılaştırma hızının üstel değerleridir. Şekil 7'de görüldüğü gibi katılaştırma hızı arttıkça elektriksel özdirenç değeri de artmıştır. Bu çalışmada elde edilen katılaştırma hızına ve mikroyapıya ait 0.12 ve 0.22 üstel değerleri Tablo 2'de verilen benzer çalışmalarla uyum içerisindedir (Kaya vd., 2013; Kaya vd., 2012).

\section{Sonuçlar}

$\mathrm{Bu}$ çalışmada, Al-\%33ağ. Cu ötektik alaşımı, Bridgman tipi kontrollü katılaştırma fırını yardımıyla, sabit sicaklık gradyenti $(G)$, farklı katılaştırma hızlarında (V), doğrusal olarak katılaştırılmış, katılaştırma parametresi ( $V)^{\prime}$ 'ne bağlı olarak mikroyap1 parametresi $(\lambda)$, mikrosertlik $(H V)$, çekme-dayanım $\left(\sigma_{u t s}\right)$, elektriksel özdirenç $(\rho)$ değerlerinin nasıl değiştiği incelenmiştir. Yapılan araştırmalardan aşağıdaki sonuçlara ulaşılmıştır.
Sonuç olarak yapılan bu çalışmada Al-033ağ. $\mathrm{Cu}$ ötektik alaşımının kontrollü katılaştırma deneyleri neticesinde lamelsel mikroyapı özellikleri göstermiştir. Analizler sonucunda ise katılaştırma hızının yaklaşık 20 kat artmasıyla mikroyap1 değerlerinin yaklaşık 5 kat azaldığ Ayrıca katılaştırma hızındaki 20 kat artış ve buna bağlı olarak mikroyapıdaki 5 kat azalış alaşımın mikrosertlik ve çekme-dayanım değerini yaklaşık 1.3 kat artırırken, elektriksel özdirenç değerini ise yaklaşık 1.5 kat artırmıştır.

\section{Teşekkür}

Bu çalışma TÜBİTAK tarafından 112T588 kodu ile desteklenmiştir. Desteklerinden dolayı TÜBİTAK' a teşekkür ederiz.

\section{Kaynaklar}

Boettinger, W.J., Coriell, S.R., Greer, A.L., Karma, A., Kurz, W., Rappaz, M. ve Trivedi, R., 2000. Solidification Microstructures: Recent Developments. Future Directions. Acta Mater, 48, 43-70.

Böyük, U., 2009. Üçlü Metalik Alaşımların Kontrollü Doğrusal Katılaştırılması ve 
Mikrosertliğinin İncelenmesi. Erciyes Üniversitesi Fen Bilimleri Enstitüsü Katıhal Fiziği Kayseri.

Çadırlı, E., Ülgen, A. ve Gündüz, M., 1999. Directional Solidification of the Aluminium-Copper Eutectic Alloy. Materials Transactions JIM, 40(9), 989996.

Cante, M.V., Spinelli, J.E., Cheung, N., ve Garcia, A., 2010. The Correlation Between Dendritic Microstructure and Mechanical Properties of Directionally Solidified Hypoeutectic Al-Ni Alloys. Met Mater-Int, $16,39$.

Das, S., Mondal, D.P., Sawla, S. ve Ramkrishnan, N., 2008. Synergic effect of reinforcement and heat treatment on the two body abrasive wear of an Al-Si alloy under varying loads and abrasive sizes. Wear, 264, 47-59.

Du, D.F., Hou, L., Gagnoud, A., Ren, Z.M., Fautrelle, Y., Cao, G.H. ve Li, X., 2014. Effect of an axial high magnetic field on Sn dendrite morphology of $\mathrm{Pb}-\mathrm{Sn}$ alloys during directional solidification. Journal of Alloys and Compounds, 588, 190-198.

Engin, S., 2013. Kontrollü Katılaştırılan Çok Bileşenli Ötektik Alaşımların, Mekanik ve Elektriksel Özelliklerinin Katılaştırma Parametrelerine Bağlılığının İncelenmesi. Erciyes Üniversitesi Fen Bilimleri Enstitüsü Katıhal Fiziği, Kayseri.

Goulart, P.R., Spinelli, J.E., Cheung, N. ve Garcia, A., 2010. The effects of cell spacing and distribution of intermetallic fibers on the mechanical properties of hypoeutectic Al-Fe alloys. Mater Chem Phys, 119, 272.

Goulart, P.R., Spinelli, J.E., Os'orio, W.R. ve Garcia, A. 2006. Mechanical properties as a function of microstructure and solidification thermal variables of $\mathrm{Al}-\mathrm{Si}$ castings. Materials Science and Engineering A, 421, 245-253.

Gündüz, M., Kaya, H., Çadırlı, E. ve Özmen, A., 2004. Interflake spacings and undercoolings in Al-Si irregular eutectic alloy. Materials Science and Engineering A-Structural Materials Properties. Microstructure and Processing, 369, 215-229.
Hecht, U., Granasy, L., Pusztai, T., Böttger, B., Apel, M., Witusiewicz, V., Ratke, L., De Wilde, J., Froyen, L., Camel, D., Drevet, B., Faivre, G., Fries, S.G., Legendre, B. ve Rex, S., 2004. Multiphase solidification in multicomponent alloys. Materials Science and Engineering, R 46, 1-49.

Jackson, K.A. ve Hunt, J.D., 1966. Lamellar and Rod Eutectic Growth, Trans. Metall. Soc. A.I.M.E, 236, 1129.

Jones, H. 2005. Some effects of solidification kinetics on microstructure formation in aluminium-base alloys. Materials Science and Engineering A, 413-414,165-173.

Kaya, H., Böyük, U., Çadırlı, E. ve Maraşlı, N. 2013. Influence of growth rate on microstructure, microhardness, and electrical resistivity of directionally solidified Al-7 wt\% Ni hypo-eutectic alloy. Met Mater-Int, 19(1), 39.

Kaya, H., Böyük, U., Çadırlı, E. ve Maraşlı, N., 2010. Unidirectional solidification of aluminium-nickel eutectic alloy. Kovove Mater, 48(5), 291.

Kaya, H., Böyük, U., Çadırlı, E. ve Maraşlı, N., 2012. Measurements of the microhardness, electrical and thermal properties of the AlNi eutectic alloy. Mater Design, 34, 707.

Kaya, H., Cadirli, E., Gündüz, M. ve Ülgen, A. 2003. Effect of the temperature gradient, growth rate, and the interflake spacing on the microhardness in the directionally solidified Al-Si eutectic alloy. Journal of Materials Engineering and Performance, 12(5), 544-551.

Kaya, H., Gündüz, M., Çadırlı, E. ve Maraşılı, N., 2009. Dependency of microindentation hardness on solidification processing parameters and cellular spacing in the directionally solidified $\mathrm{Al}$ based alloys. Journal of Alloys and Compounds, 478, 281-286.

Li, X., Fautrelle, Y. ve Ren, Z., 2007. Influence of thermoelectric effects on the solid-liquid interface shape and cellular morphology in the mushy zone during the directional solidification of $\mathrm{Al}-\mathrm{Cu}$ alloys under a magnetic field. Acta Materialia, 55, 38033813. 
Li, X., Ren, Z. ve Fautrelle, Y., 2006. Effect of a high axial magnetic field on the microstructure in a directionally solidified $\mathrm{Al}-\mathrm{A} 12 \mathrm{Cu}$ eutectic alloy. Acta Materialia, 54, 5349-5360.

Miller, J.D. ve Pollock, T.M., 2014. Stability of dendrite growth during directional solidification in the presence of a non-axial thermal field. Acta Materialia, 78, 23-36.

Min, Q.U., Lin, L.I.U., Yan, C.U.I. ve Feng-bin, L.I.U., 2015. Interfacial morphology evolution in directionally solidified $\mathrm{Al}-1.5$ $\% \mathrm{Cu}$ alloy, Trans. Nonferrous Met. Soc. China, 25, 405-411.

Ourdjini, A., Liu, J. ve Elliott, R., 1994. Eutectic Spacing Selection in Al-Cu System. Mater Sci Tech-Lond, 10, 312.

Paliwal, M. ve Jung, I., 2013. The evolution of the growth morphology in $\mathrm{Mg}-\mathrm{Al}$ alloys depending on the cooling rate during solidification. Acta Materialia, 61, 4848-4860.

Peres M.D., Siqueira C.A.ve Garcia A., 2004. Macrostructural and microstructural development in $\mathrm{Al}-\mathrm{Si}$ alloys directionally solidified under unsteady-state conditions. Journal of Alloys and Compounds, 38, $168-181$.
Rana R.S., Purohit R. ve Das S., 2012. Reviews on the Influences of Alloying Elements on the Microstructure and Mechanical Properties of Aluminum Alloys and Aluminum Alloy Composites. International Journal of Scientific and Research Publications, 2, 1-7.

Silva B.L., Araujo I., Silva W.S., Goulart P.R., Garcia A. ve Spinelli J.E., 2011. Correlation between dendrite arm spacing and microhardness during unsteady-state directional solidification of Al-Ni alloys. Phil Mag Lett 91, 337.

Silva B.L., Garcia A. ve Spinelli J.E., 2012. The effects of microstructure and intermetallic phases of directionally solidified Al-Fe alloys on microhardness. Mater Lett, 89, 291.

Smiths F.M., 1958. Measurement of Sheet Resistivities with the Four-Point Probe. The Bell Sys. Tech. J, 37, 711.

Walker H., Shan Liu, Lee J.H. ve Trivedi R., 2007. Eutectic Growth in Three Dimensions. Metallurgical And Materials Transactions A, 38A, 1417-1425. 